\title{
Research on the Reasons and Countermeasures of Telephone Sales Staff Demission Based on ERG Theory
}

\author{
Zhang Hong \\ School of Management, Shanghai University, 20 Cheng Zhong Street, Shanghai, 201800, China
}

\begin{abstract}
In the increasingly fierce competition in the modern society, human resources are the primary resources, the development of any industry and company depends on the contribution of people, but the fast-growing development of telephone sales industry has been plagued by high demission rate. On the basis of previous studies, this article combines the demission feedback dates of an Internet marketing company's telephone sales staff, trying to start from the ERG theory for further analysis on reasons of leaving and put forward corresponding countermeasures. Which aiming to help companies to retain talents and achieve the common development of employees and companies.
\end{abstract}

Keywords: demission; ERG theory; countermeasures

DOI: $10.7176 / \mathrm{EJBM} / 11-18-22$

Publication date:June $30^{\text {th }} 2019$

\section{Introduction}

With the development of market economy reforms, labor markets are becoming more flexible, modern company's staff demission has become commonplace fact. According to the "turnover and salary " research report released by 51 job.com recently, the average annual demission rate of 19 industries in China is $18.5 \%$, showing a trend of increasing year by year, at the same time, the average annual turnover rate among sales staff is far more than the industry average. Telephone Sales staff as a specific group of the sales staff, along with the emergence of the rapid development of the mobile communication industry, which is the most frequent departure of all sales jobs. If you open any recruitment website and you can see that the telephone sales company is recruiting almost all the year round. According to relevant statistics show, the monthly telephone sales staff demission rate of around $8 \%$ to $10 \%$, that is to mean, among 100 telephone sales staffs, nearly 10 sales employees are leaving every month for various reasons. It is often seen in the company that three or four sales employees are resigned at the same day, or even the whole group leaving. Among all employees who have left, more than $80 \%$ apply for resignation voluntarily, only $20 \%$ of telephone sales employees are dismissed by the company due to poor performance or violation of rules and regulations. Voluntary demission rate in new employees is higher than old employees, all of those have caused huge losses to the company.

In order to make up for the staff vacancies caused by the high turnover rate, company has to invest more funds in recruiting and training new employees that constitute the replacement capital of employee demission. At the same time, telephone sales staff who eventually leave the company often experience a period of low productivity without leaving the company, which becomes a potential business risk for the company. In addition, the demission of employees with excellent performance will cause great psychological impact to other employees around. So, what are the reasons why most telephone sales staff chose to leave is a problem that every human resource management personnel of the marketing sales company often thinks about. How to grasp the demand characteristics of the telephone sales staff, recruit and retain excellent sales staff, has been the focal point and difficult point in the management of Telemarketing business. Company can't be limited to recruiting work, "leaving a wave, recruiting a wave" is a temporary way to solve the demission problem, Company can understand the characteristics of employees in the telephone sales industry, analyze the real reasons behind the high turnover of the sales staff from the individual needs, help companies better to retain employees and motivate employees to realize their self-value in the process of creating value for the organization.

\section{Related Concept and Theoretical Basis}

2.1 The concept of telephone sales

Telephone sales originated in the United States. With the rapid development of communication technology, it has been applied in the fields of network services, investment consulting, insurance, decoration design, electronic commerce, education and training, automobile, real estate, etc. It is a kind of sales position based on telephone, the salesman directly contacts with a specific customer in the name of the company, completes the promotion of the company's products or services, including consultation, quotation and confirmation of the terms of the products. China is one of the most promising places in the world for telephone sales. At present, the number of all kinds of telephone salesman in China has exceeded 30 million, which is a hot job in a large number of industries in China. As a company, the telephone sales model is also the most cost-effective way to contact potential customers directly only with a single phone. If a staff calls out 300 phone numbers per day, about $10 \%$ can be the potential customers, 
perhaps in this $10 \%$ customers, there is a productive client, which is a very high input-output ratio of business operation model, it will have a long development prospect.

\subsection{The characteristics of telephone sales}

The telephone sale is an effective business operation model, and the success of this model depends on the role of talents. To do a good job of telephone sales staff demission management, you must learn about the characteristics of telephone sales: (1) From the perspective of job responsibilities, it is mainly responsible for promoting and selling products or services, accomplishing performance goals, including the development of new customers and the maintenance of old customers. (2) In terms of qualifications, the candidate recruited in the market require junior college and above, under the age of 30, good health, good communication and learning ability, positive attitude and strong resistance to stress. (3) From the point of view of labor intensity, telephone sales position has the minimum effective call duration requirement, and the average daily working time of employee is 10 hours or more. (4) From the perspective of career development, the telephone sales staff can be transferred from the sales training students and then they can be promoted to senior sales, key account managers, regional sales manager, national sales manager, marketing director, CEO and so on. Therefore, telephone sale is not a simple and repetitive work that the technology is not high and development is limited.

\subsection{ERG theory}

Why are so many sales staff frequently leaving? Scholars in organizational behavioral research believe that the main reason for an employee to leave their organization is that the demand is not being met. In accordance with Maslow need hierarchy theory, Clayton, an American scholar, who proposed ERG theory that may help us better understand the individual needs of telephone sales employee and provide guidance on turnover management. ERG theory assumes that a human being has three core needs that he strives to meet. They include obtaining his material existence needs, maintaining his interpersonal relatedness with significant other people, and seeking opportunities for his unique personal development and growth, these needs provide the basic elements in motivation. People often express their wants in the form of complex goals which may include mixtures of the basic needs. One such "compound" need would be for a promotion, where as a result of the promotion the person would obtain more material rewards in the form of pay, a different constellation of interpersonal relationships, and new opportunities to develop and utilize his talents. In addition, Unlike Maslow need hierarchy theory, ERG theory agrees that Employees' responses to these three needs are not incremental, and frustration with one may be supplemented by satisfaction with the other. In the company human resource management, we must fully understand the needs of employees, and on the basis of ensuring the basic interests of the company, we must respect the needs of employees to the greatest extent, or do a good job of meeting alternative need to control the turnover of employees effectively.

\section{The Reasons for the Demission of Telephone Sales Staff}

This study selects an Internet marketing company in East China as the research object, based on the practical experience of the company, analyzes the satisfaction of the needs of the demission telephone sales staff based on the ERG theory, summarizes the reasons for the turnover, and expects to apply the conclusion to the management of the sales staff in other industries. B company marketing center in Shanghai was established in 2005, becoming one of the largest Internet marketing company in china, after more than ten years of business expansion, the demand for people in company B has increased rapidly, especially for the telephone sales employee in the customer development department. Because of the company's large investment in recruitment and the company's good branding in the industry, the recruitment of telephone sales staff has been able to meet or exceed the recruitment plan. However, in recent years, the demission rate of the company's sales staff has remained high, hindering the long-term development of the company. In this research, we use the inductive method to analyze demission staff whether to leave a job because a certain need is not being met through information about report resignation and exit interview between September 2018 to February 2019. According to ERG theory, we classify the 8 requirements that account for a large proportion and lead to turnover. The specific situation is shown in table 1:

Table 1. Classification of B company's staff core needs based on ERG theory

\begin{tabular}{|c|c|c|}
\hline Existence needs & Interrelationship needs & Growth needs \\
\hline Salary & Harmony with superiors & Sense of work \\
Work stability & Harmony with colleagues & Career development plan \\
& Customer respect \\
Job identity & \\
\hline
\end{tabular}

There is more than one-third of employees mentioned meet the material needs for existence in three core needs. Salary is still the primary focus of the new generation of telephone sales staff, the company's remuneration will directly affect employee turnover intention. B company is located in the suburbs of Shanghai, the salaries of telephone sales staff include a base salary, commission component and other benefits, salary level is on an average 
level in industry. If telephone sales staffs are unable to earn their expected income, some of them leave for higherpaying educational sales, but more may leave big cities to find another job.

The exit interview records of the employees waiting to leave reveal that the direct reason for employees to leave the organization is unsatisfied interrelationship needs with superiors, colleagues and customers. Telephone sales staff not only didn't feel the encouragement and support from superiors, guidance and help from colleagues, but also had the pressure of performance from superiors, competition from colleagues and uncivilized treatment from customers. Young telephone sales staffs are aggressive, competitive and have high self-esteem, which leads to more and more rebellious psychology, thus resulting in turnover intention.

Finally, we found that salesman who had worked for more than three months pay more attention to their career development plan, they hoped that the organization could map out a clear path to promotion for telephone sales staff, when this hope fails, they are most determined to leave.

\section{Discussion and Countermeasures}

Ma Yun once said that there were many reasons for employees to leave their jobs. Only two points are the most real. First, money is not given. Second, the heart is wronged. This is more prominent in the telephone sales industry. Based on the above analysis, although the main telephone sales staff is the generation after 90s who pursue autonomy and challenge themselves, their primary concern is existence needs, a stable and competitive salary can help us retain most of our employees. Second, unsatisfied demand of interrelationship needs is the direct cause of most demission. Finally, sales staffs who have been working for a few months will gradually pay attention to their career, organizations that lack long-term planning for employees will inevitably lead to a high demission rate. Therefore, this paper proposes the following solutions:

\subsection{Provide competitive salary}

Anyone with independent thinking has different expectations for his salary level. Naturally, it will be compared with the salary of other companies in the same industry. When similar jobs in the market are found to pay more than the current company, it may have idea to leave. As a result, the paid by the company should be based on the basic living standard of the employees, not lower than the market average. The goal of HR management staff is not to pay less to employees, but to motivate employees to create greater value for the organization in the context of generous pay. Most of telephone sales staffs are not local people, and the living cost of working in a big city is high, so they are willing to pay more time and energy to work hard unless make sure that they can survive where the company is located. Currently, the salary design of telephone sales staff is not standardized, the basic salary is too low, and the proportion of commission is not clear. Recruiters will attract employees who enter the company by drawing big cakes. If there is no competitive salary support, they will leave. At the same time, telephone sales staffs at this stage generally have received higher education, strong sense of labor law, company needs to provide employees with insurance, provident fund and other necessary benefits to retain employees

\subsection{Establish a harmonious organizational culture}

Employee demission is not necessarily a dissatisfaction with work or compensation, or it may be a problem with the interpersonal relationship with others. Abusive supervision, stress management, workplace ostracism and knowledge hiding, all of those affect the interrelationship needs of telephone sales staffs. As a superior, you should give more encouragement and support to your staff. When employees perform well, you should give affirmation and make employees feel the sense of accomplishment of work progress. Telephone sales staffs face a large performance pressure which directly affects the turnover intention of telemarketing employees. Once the salesman can't get the contract for a long time, he will bear the increasing psychological pressure and worry about not finishing the task on time. The superior should assume the responsibility of the manager, help the sales staff to analyze problems and find solutions. Company can build a sharing and learning organizational culture, and hold regular group business progress discussion activities. During the discussion, an open working atmosphere can be established to fully encourage employees to put forward questions and make suggestions. In addition, due to population characteristics for younger workers, we are supposed to organize team recreational activities, such as outdoor travel at weekend, dinner party after work, to enhance the exchange of feelings between employees through the easy activities to promote emotional communication, the formation of cohesion.

\subsection{Build a good career promotion channel}

Build a good promotion mechanism within the organization and customize career planning for employees. This strategy is mainly for telephone sales staffs who have worked for a period of time and are interested in long-term development. Telephone sales staffs often have a sense of insecurity in the company, the main reason is that few employees make sales as their lifelong profession. They often don't know their career path and don't know how to work hard. Employees not only want to get material returns, but also hope that they can continue to grow. Career promotion channel is an important factor in the growth of employees, managers should establish professional 
development paths for their employees from the time they join the company. For telephone sales staffs with outstanding performance, the company provides a vertical development path, and provides opportunities for salesmen who have a low performance or want to change careers to help them find a new position that suits them. Good career planning helps employees find career paths that are suitable for their long-term development, thereby reducing employees' sense of insecurity and ensuring that employees can stay in the company.

\subsection{Reduce the uncivilized treatment of staff by customers}

When telephone sales staffs recommend the company's products to customers, they are often treated with customer apathy and even bad words. which is self-esteem hit for employees, if working for a long time by the blow of selfesteem, will affect the working emotion, even serious psychological disease, resulting in the turnover of employees. To the uncivilized treatment by unfamiliar customers, we can only start from ourselves and strengthen the sales skills training to minimize this phenomenon. On the other hand, some customers have already contacted many times who have no intention of cooperation. In the era of big data, we can use technology to identify these Numbers in advance and reduce the frequency of uncivilized treatment of employees in telephone communication, so that telephone sales staffs will not leave the organization due to impaired self-esteem.

\subsection{Other countermeasures}

Many companies have found through research that telephone sale staffs have a strong need for work-life balance. As a result, company can adopt a series of flexible measures aimed at these needs. For example, flexible work hours, starting at $10 \mathrm{am}$, but maintain a total number of hours per day. Company can also contact some service agencies to provide employees with living coupons, such as haircut cards, fitness cards in order to allow employees to enjoy life.

\section{Conclusion}

The reasons for the phenomenon of high demission of telephone sales staffs are various, and the countermeasures also need to be considered comprehensively. But not all the leaving of employees is bad, reasonable staff turnover can help us select suitable talents in this industry. Attracting and retaining these suitable employees is something that every telemarketing company should consider carefully

\section{References}

Alderfer, C. P. (1969). An empirical test of a new theory of human needs. Organizational behavior and human performance, 4(2), 142-175.

Fan, L. U. O., Jin-nuo, L. I. U., \& Ben-lin, Z. H. U. (2008). Causes and Precontrol Strategies of the Core Staff's Demission in Airline Companies [J]. Journal of Wuhan University of Technology (Social Sciences Edition), 3.

Guoan, Y., Qi, Y., \& Huawei, M. (2008). The Relationship between Pre-entry Expectations and Employees' Turnover: An Examination of Met-expectation Hypothesis in Chinese Firms' Context [J]. Nankai Business Review, 3.

Guo Tian, Lin Feng. (2018). Study on the motivation of knowledge worker based on ERG theory. China Forestry Economics, 03, 41-44.

Research report on Turnover and Salary, http://rearch.51.job.com/insight-416.html, 2018-12-27

Sheridan, J. E. (1992). Organizational culture and employee retention. Academy of management Journal, 35(5), 1036-1056.

Weng, Q. X., \& Hu, B. (2009). The structure of career growth and its impact on employees' turnover intention. Industrial Engineering and Management, 14(1), 14-21.

Xiong Manli (2017). Research on Customer Service Representative's Turnover Intention and Countermeasures for Credit card Call Center. Huazhong University of Science and Technology. 